Article

\title{
In Vitro Comparison of Antibacterial and Antibiofilm Activities of Selected Fluoroquinolones against Pseudomonas aeruginosa and Methicillin-Resistant Staphylococcus aureus
}

\author{
Majed M. Masadeh ${ }^{1, *}$, Karem H. Alzoubi ${ }^{2}{ }^{\oplus}$, Wesam S. Ahmed ${ }^{2}\left(\mathbb{D}\right.$ and Aisha S. Magaji ${ }^{3}$ \\ 1 Department of Pharmaceutical Technology, Jordan University of Science and Technology, Irbid 22110, Jordan \\ 2 Department of Clinical Pharmacy, Jordan University of Science and Technology, Irbid 22110, Jordan; \\ khalzoubi@just.edu.jo (K.H.A.); wisamyejo@yahoo.com (W.S.A.) \\ 3 Department of Applied Biology, Jordan University of Science and Technology, Irbid 22110, Jordan; \\ magajiaisha22@gmail.com \\ * Correspondence: mmmasadeh@just.edu.jo; Tel.: +962-272-01000; Fax: +962-27201075
}

Received: 7 December 2018; Accepted: 21 January 2019; Published: 24 January 2019

\begin{abstract}
An in vitro overview of the inhibitory effects of selected fluoroquinolones against planktonic and biofilm cells of the methicillin-resistant Staphylococcus aureus (MRSA) strain American type culture collection (ATCC) 43300 and the Pseudomonas aeruginosa strain ATCC 27853 was carried out. Biofilm cells of both strains were less susceptible to the selected antibiotics than their planktonic counterparts. In addition, certain antibiotics were more effective against biofilm cells, while others performed better on the planktonic cells. Against P. aeruginosa, ciprofloxacin was the most potent on both planktonic and biofilm cells, whereas ofloxacin was the least potent on both biofilm and planktonic cells. Moxifloxacin and gatifloxacin were the most potent against both planktonic and biofilm MRSA bacteria, however, not in the same order of activity. Norfloxacin was the least active when tested against both planktonic and biofilm cells. The results of this work are expected to provide insight into the efficacy of various fluoroquinolones against MRSA and Pseudomonas aeruginosa biofilms. This study could form the basis for future clinical studies that could recommend special guidelines for the management of infections that are likely to involve bacteria in their biofilm state.
\end{abstract}

Keywords: biofilm; fluoroquinolones; methicillin-resistant Staphylococcus aureus; planktonic; Pseudomonas aeruginosa

\section{Introduction}

A biofilm represents a structured, organized, and complex group of sessile bacterial cells attached to a surface, which grow and interact as a community [1]. Bacterial biofilms are associated with human diseases, and account for $80 \%$ of bacterial chronic inflammatory and infectious diseases [2]. Compared to planktonic cells, biofilms are characterized by significant loss of susceptibility to antibiotics as well as high virulence potential [3], which explains why biofilms are associated with a tremendous impact on health, including increased morbidity and mortality [4]. Moreover, complications related to biofilms often result in additional hospitalization and medical care for patients, leading to substantial economic consequences [5].

Staphylococcus aureus and Pseudomonas aeruginosa are medically significant microbes that are capable of forming biofilms [3]. Methicillin-resistant Staphylococcus aureus (MRSA) is a major cause of hospital-acquired infections that are becoming more difficult to combat because of the development of bacterial resistance to most of the current antibiotics [6]. About $52.3 \%$ of intensive care unit nosocomial 
infections are due to MRSA [7]. As a result, biofilm formation contributes to the spread of MRSA in community and hospital settings. It also prolongs the duration of MRSA infection and colonization [8]. Similarly, P. aeruginosa is responsible for several opportunistic infections in immunocompromised patients. It is responsible for chronic lung infections in cystic fibrosis patients [9,10]. It is also the causative agent of urinary tract infections, septicemia, osteomyelitis, endocarditis [11], pneumonia, and burn infections [12].

The fluoroquinolones (FLQs) are a group of synthetic broad-spectrum antibiotics that inhibit bacterial cell replication by interfering with two enzymes that are essential in the process: DNA gyrase (topoisomerase II) and topoisomerase IV [13]. The FLQs are suitable for the treatment of urinary tract infections, gastrointestinal tract infections, respiratory tract infections, sexually transmitted infections, and skin infections $[14,15]$. They are effective on a variety of pathogens including P. aeruginosa, Mycoplasma spp., Chlamydia spp., Staphylococcus spp., and Streptococcus spp. [16]. The FLQs have several favorable properties, such as high potency, broad-spectrum activities, good tissue permeability, excellent bioavailability, and relatively few side effects. They are also available in both oral and intravenous formulations $[17,18]$.

\section{Materials and Methods}

\subsection{Bacterial Strains}

Methicillin-resistant Staphylococcus aureus (MRSA) strain ATCC 43300 and Pseudomonas aeruginosa strain ATCC 27853 (Microbiologics, USA) were used in this study.

\subsection{Antibacterial Agents}

The following FLQs were used in this study: ciprofloxacin (Hikma Pharmaceutical: Amman, Jordan), gatifloxacin (Allergen Pharmaceuticals: Dublin, Ireland), levofloxacin (Sanofi-Aventis Deutschland GmbH: Frankfurt, Germany), moxifloxacin (Alcon Laboratories: Fort Worth, TX, USA), norfloxacin (Amman Pharmaceutical industries: Amman, Jordan), and ofloxacin (Allergen Pharmaceuticals, Ireland).

\subsection{Antibacterial Susceptibility Test}

The susceptibility of planktonic forms of MRSA and P. aeruginosa to the FLQs was assessed through the agar-well diffusion assay [19]. Sterilized Mueller-Hinton agar (MHA) plates were uniformly inoculated with the standardized bacterial suspension $\left(1 \times 10^{8} \mathrm{CFU} / \mathrm{mL}\right)$ using sterile cotton swabs, and then the plates were allowed to dry for five minutes. A sterile cork borer was used to make holes of $6 \mathrm{~mm}$ diameter in each plate. Wells were loaded with $100 \mu \mathrm{L}$ of each antibiotic (stock solution concentration was $10 \mu \mathrm{g} / \mathrm{mL}$, where all antibiotics were dissolved in distilled water), thus, equal concentrations of each drug were placed in each corresponding well. Negative control wells were loaded with $100 \mu \mathrm{L}$ of sterile broth and bacterial suspension (no antibiotic). Each treatment was replicated three times and plates were incubated for $24 \mathrm{~h}$ at $37^{\circ} \mathrm{C}$. After the incubation period, the plates were examined for growth inhibition and the diameters of inhibition zones were measured using a standard ruler and recorded. In another experiment, the minimum inhibitory concentration (MIC) and minimum bactericidal concentration (MBC) values of the selected FLQs against both MRSA and P. aeruginosa planktonic forms were determined using the broth microdilution method [20]. Briefly, a two-fold serial dilution of the FLQs was carried out in a 96-well microtiter plate in accordance with the Clinical and Laboratory Standards Institute (CLSI) (2012) guidelines. A $100 \mu \mathrm{L}$ aliquot of the adjusted bacterial suspension $\left(5 \times 10^{5} \mathrm{CFU} / \mathrm{mL}\right)$ was added into wells containing $100 \mu \mathrm{L}$ of serially diluted antibiotics. Growth control and sterility control wells were inoculated with $200 \mu \mathrm{L}$ of bacterial suspension and phosphate-buffered saline (PBS), respectively. The microtiter plate was then incubated at $37^{\circ} \mathrm{C}$ for $18-24 \mathrm{~h}$. Plates were assessed for growth visually and by measuring the optical density at $630 \mathrm{~nm}$ using a microtiter plate reader. Wells with the lowest antibiotic concentration that were visually clear and had an optical density of less than 0.1 were considered as the MIC for the selected FLQ. MBC 
was determined by inoculating $10 \mu \mathrm{L}$-aliquots from clear wells (of MIC of the particular antibiotic and higher) onto MHA. The plates were incubated at $37^{\circ} \mathrm{C}$ for $18-24 \mathrm{~h}$. The plates were examined for bacterial growth as described above for the MIC determination experiment, and the lowest antibiotic concentration that showed no growth was considered the MBC for the chosen antibiotic. For both MIC and MBC determination, a negative control was included, and it contained sterile broth and bacterial suspension (zero antibiotic concentration), and a positive control was chosen as the highest concentration of the particular antibiotics used.

\subsection{Biofilm Assay and Determination of Minimum Biofilm Eradication Concentration (MBEC)}

The assay was carried out using the Calgary 96-well Biofilm Device (Innovotech Inc.: Edmonton, $\mathrm{AB}$, Canada) as previously described in [21]. Briefly, bacterial suspension was adjusted to $1 \times 10^{7} \mathrm{CFU} / \mathrm{mL}$. The biofilm device was inoculated by adding $150 \mu \mathrm{L}$ of the inoculum into the wells of the 96 peg-lids on which the biofilm cells could build up. Sterility wells were inoculated with $150 \mu \mathrm{L}$ of PBS. The pegs were incubated in a humidified incubator for 18-24 $\mathrm{h}$ under a rotation of $110 \mathrm{rpm}$ at $37^{\circ} \mathrm{C}$ to allow biofilm formation on the purpose-designed pegs. Once the biofilms were allowed to form, the pegs were rinsed with phosphate-buffered saline (PBS) to remove planktonic cells. Each peg-lid was then transferred into a "challenge 96-well microtiter plate" containing $200 \mu \mathrm{L}$ of serially diluted antibiotics. Growth control wells and sterile control wells were filled with $200 \mu \mathrm{L}$ of mycorrhiza helper bacteria (MHB) and PBS, respectively. The peg lids in the challenge plate were then incubated for $18-24 \mathrm{~h}$ at $37^{\circ} \mathrm{C}$. Finally, the peg lids were removed from the challenge plate and rinsed with PBS, then transferred into the recovery plate containing $200 \mu \mathrm{L}$ of MHB in each well. The plate was incubated overnight at $37^{\circ} \mathrm{C}$.

To determine the MBEC values, the recovery plate was assessed visually for turbidity, and by measuring the optical density at $630 \mathrm{~nm}$ using a microtiter plate reader. Any visible growth indicated the detachment and re-growth of bacterial cells from the treated biofilms. The MBEC value represents the minimum antibiotic concentration that eradicates the biofilm following a suitable period of incubation [22]. Thus, the lowest antibiotic concentration that showed wells with no growth — visually clear with measured optical density of less than 0.1 -was considered the MBEC for the selected antibiotic.

\section{Results}

\subsection{Zones of Inhibition}

The agar-well diffusion method was used to determine the zones of inhibition (ZOIs) of the selected FLQs against MRSA and P. aeruginosa planktonic cells. Among FLQs, moxifloxacin (33.8 mm) and gatifloxacin $(32 \mathrm{~mm})$ had the largest ZOIs against MRSA, while ciprofloxacin $(30 \mathrm{~mm})$ and gatifloxacin $(22 \mathrm{~mm})$ showed the highest ZOI diameters against $P$. aeruginosa. Table 1 shows each antibiotic with its respective ZOI measured in millimeters $(\mathrm{mm})$. Data were obtained from three independent experiments.

Table 1. Zone of inhibition of the selected fluoroquinolones (FLQs) against methicillin-resistant Staphylococcus aureus (MRSA) and Pseudomonas aeruginosa planktonic cells.

\begin{tabular}{ccc}
\hline Fluoroquinolone & $\begin{array}{c}\text { Diameter of the Zone of } \\
\text { Inhibition } \mathbf{( m m )} \text { against MRSA }\end{array}$ & $\begin{array}{c}\text { Diameter of the Zone of Inhibition } \\
(\mathbf{m m}) \text { against } \boldsymbol{P} \text {. aeruginosa }\end{array}$ \\
\hline Ciprofloxacin & $22.8 \pm 0.8$ & $30.3 \pm 0.6$ \\
Gatifloxacin & $32.0 \pm 0.0$ & $22.3 \pm 0.6$ \\
Levofloxacin & $26.3 \pm 0.6$ & $21.0 \pm 1.0$ \\
Moxifloxacin & $33.8 \pm 0.3$ & $19.3 \pm 1.5$ \\
Norfloxacin & $10.6 \pm 0.5$ & $21.3 \pm 1.2$ \\
Ofloxacin & $22.3 \pm 0.3$ & $16.0 \pm 1.0$ \\
\hline
\end{tabular}

Data are represented as mean \pm standard deviation. 


\subsection{Minimum Inhibitory Concentration (MIC)}

The MIC of the selected FLQs was determined against both MRSA and P. aeruginosa planktonic strains using the broth microdilution method. Among FLQs, moxifloxacin (MIC $=0.049 \mu \mathrm{g} / \mathrm{mL}$ ) and ciprofloxacin (MIC $=0.26 \mu \mathrm{g} / \mathrm{mL}$ ) had the highest in vitro activity against MRSA and P. aeruginosa, respectively. The lowest MIC values were that of norfloxacin $(1.172 \mu \mathrm{g} / \mathrm{mL})$ against MRSA, and ofloxacin $(3.33 \mu \mathrm{g} / \mathrm{mL})$ against $P$. aeruginosa (Table 2$)$.

Table 2. Minimum inhibitory concentration (MIC) and minimum bactericidal concentration (MBC) values of FLQs against MRSA and P. aeruginosa planktonic cells.

\begin{tabular}{ccccc}
\hline & \multicolumn{2}{c}{ MRSA } & \multicolumn{2}{c}{ P. aeruginosa } \\
\hline Fluoroquinolone & MIC $(\mu \mathrm{g} / \mathrm{mL})$ & MBC $(\mu \mathrm{g} / \mathbf{m L})$ & MIC $(\mu \mathrm{g} / \mathbf{m L})$ & MBC $(\mu \mathrm{g} / \mathbf{m L})$ \\
\hline Ciprofloxacin & $0.235 \pm 0.084$ & $0.625 \pm 0.00$ & $0.26 \pm 0.09$ & $0.31 \pm 0.00$ \\
Gatifloxacin & $0.078 \pm 0.00$ & $0.156 \pm 0.00$ & $0.63 \pm 0.00$ & $0.63 \pm 0.00$ \\
Levofloxacin & $0.156 \pm 0.00$ & $0.313 \pm 0.00$ & $1.04 \pm 0.36$ & $1.25 \pm 0.00$ \\
Moxifloxacin & $0.049 \pm 0.018$ & $0.0781 \pm 0.00$ & $1.67 \pm 0.72$ & $2.5 \pm 0.00$ \\
Norfloxacin & $1.172 \pm 0.221$ & $2.5 \pm 0.00$ & $0.83 \pm 0.36$ & $1.25 \pm 0.00$ \\
Ofloxacin & $0.352 \pm 0.11$ & $0.625 \pm 0.00$ & $3.33 \pm 1.44$ & $5.00 \pm 0.00$ \\
\hline
\end{tabular}

Data are represented as mean \pm standard deviation.

\subsection{Minimum Bactericidal Concentration (MBC)}

The MBCs of the six FLQs were determined to assess the concentrations of these FLQs that can permanently kill the planktonic cells. All six FLQs had MBC values that were always higher than their MIC, indicating that these antibiotics are not bactericidal at the MIC. The only exception was gatifloxacin, which had an MBC value that was identical to its MIC against P. aeruginosa (Table 2).

\subsection{Minimum Biofilm Eradication Concentration (MBEC)}

The MBEC values of the selected FLQs were determined using the Calgary Biofilm Device. The term MBEC refers to the concentration that prevents the regrowth of the bacteria following an overnight incubation in a recovery media of the antibiotic treated biofilms [22]. Gatifloxacin $(328.13 \mu \mathrm{g} / \mathrm{mL})$ and moxifloxacin $(390.63 \mu \mathrm{g} / \mathrm{mL})$ were the most potent against MRSA biofilm. On the other hand, ciprofloxacin $(40 \mu \mathrm{g} / \mathrm{mL})$ was the most potent against $P$. aeruginosa biofilm, followed by norfloxacin, which had an MBEC value of $160 \mu \mathrm{g} / \mathrm{mL}$. Norfloxacin $(875 \mu \mathrm{g} / \mathrm{mL})$ and ofloxacin $(640 \mu \mathrm{g} / \mathrm{mL})$ were the least potent against MRSA and P. aeruginosa biofilms, respectively (Table 3).

Table 3. Minimum biofilm eradication concentration (MBEC) values of FLQs against biofilm cells of MRSA and P. aeruginosa.

\begin{tabular}{ccc}
\hline Fluoroquinolone & $\begin{array}{c}\text { MBEC }(\mu \mathrm{g} / \mathrm{mL}) \\
\text { against MRSA Biofilm }\end{array}$ & $\begin{array}{c}\text { MBEC }(\boldsymbol{\mu g} / \mathrm{mL}) \\
\text { against } \boldsymbol{P} \text {. aeruginos } \text { Biofilm }\end{array}$ \\
\hline Ciprofloxacin & $438 \pm 125$ & $40 \pm 0$ \\
Gatifloxacin & $328 \pm 94$ & $533 \pm 185$ \\
Levofloxacin & $625 \pm 0$ & $320 \pm 0$ \\
Moxifloxacin & $390 \pm 156$ & $427 \pm 185$ \\
Norfloxacin & $875 \pm 250$ & $160 \pm 0$ \\
Ofloxacin & $750 \pm 0$ & $640 \pm 0$ \\
\hline
\end{tabular}

Data are represented as mean \pm standard deviation.

\subsection{Comparison of Antibacterial Activities of Fluoroquinolones}

In this study, we demonstrated that the activities of the six FLQs varied between planktonic and biofilm cells. Moxifloxacin and gatifloxacin were the most potent against both planktonic and biofilm MRSA bacteria, however, not in the same order of activity. Norfloxacin was the least active when tested 
against both planktonic and biofilm cells. Against $P$. aeruginosa, ciprofloxacin was the most potent on both planktonic and biofilm cells, and ofloxacin remained the least potent on both biofilm and planktonic cells. However, gatifloxacin, levofloxacin, moxifloxacin, and norfloxacin showed moderate activity that differed between the planktonic and biofilm cells. Table 4 shows the in vitro order of decreasing activity of the selected FLQs.

Table 4. Comparison of antibacterial activities of FLQs in decreasing order.

\begin{tabular}{ccccc}
\hline & \multicolumn{2}{c}{ Against Planktonic Cells } & \multicolumn{2}{c}{ Against Biofilm } \\
\hline Order of Activity & MRSA & P. aeruginosa & MRSA & P. aeruginosa \\
\hline 1 & Moxifloxacin & Ciprofloxacin & Gatifloxacin & Ciprofloxacin \\
2 & Gatifloxacin & Gatifloxacin & Moxifloxacin & Norfloxacin \\
3 & Levofloxacin & Norfloxacin & Ciprofloxacin & Levofloxacin \\
4 & Ciprofloxacin & Levofloxacin & Levofloxacin & Moxifloxacin \\
5 & Ofloxacin & Moxifloxacin & Ofloxacin & Gatifloxacin \\
6 & Norfloxacin & Ofloxacin & Norfloxacin & Ofloxacin \\
\hline
\end{tabular}

\section{Discussion}

In this confirmatory study, the susceptibility pattern of P. aeruginosa towards the selected FLQs was assessed through the determination of zones of inhibition using the agar-well diffusion method. The data obtained from the current study revealed that all the selected FLQs showed considerable growth inhibitory zones, although the susceptibility of P. aeruginosa to these antibiotics varied from high to moderate. Ciprofloxacin measured the lowest MIC among all other FLQs, which is in agreement with previous studies [11,23]. For other FLQs (i.e., gatifloxacin, norfloxacin, and levofloxacin), MICs showed that they were equally potent against $P$. aeruginosa, which is again in confirmation of previous studies [24]. Furthermore, P. aeruginosa was found to have improved susceptibility to levofloxacin as compared to Escherichia coli, Staphylococcus aureus, and Klebsiella pneumoniae [25]. Based on data obtained from zones of growth inhibition of P. aeruginosa, FLQs can be listed in order of decreasing anti-pseudomonal activity as ciprofloxacin, gatifloxacin, norfloxacin, levofloxacin, moxifloxacin, and ofloxacin. A similar conclusion was attained in a previous study of the susceptibility of P. aeruginosa to five FLQs using the disc diffusion method, where it was reported that ciprofloxacin was the most potent among FLQs followed by levofloxacin, norfloxacin, and lastly ofloxacin [26].

Regarding the MBC, all six FLQs had MBC values that were approximately two-fold higher than their MICs. This indicates that the bactericidal (killing effect) of these agents is achieved at a higher concentration than the MIC. The only exception was gatifloxacin, which had similar MIC and MBC values against $P$. aeruginosa. An early published study reported that ciprofloxacin had Minimum Bactericidal Concentration 50 (MBC50) and Minimum Bactericidal Concentration 90 (MBC90) values that were twice as large as its Minimum Inhibitory Concentration 50 (MIC50) and Minimum Inhibitory Concentration 90 (MIC90), respectively, [27] against MRSA, which is consistent with current findings. A similar conclusion was observed in a later study stating that the MBC50s of ciprofloxacin, ofloxacin, and norfloxacin were two times greater than their MIC50 values [28]. In spite of the previous facts, FLQs are still regarded as bactericidal according to the NCCLS (1999) criteria, which defines the bactericidal activity as a ratio of MBC to MIC of greater than four.

The susceptibility study of $P$. aeruginosa biofilm to the selected FLQs was carried out by the use of the Calgary Biofilm Device to determine the minimum biofilm eradication concentration (MBEC). Several studies have indicated that biofilm bacteria are less susceptible than their planktonic counterparts $[3,29,30]$. Ciprofloxacin was shown to be the most active against biofilm cells, having an MBEC of $40 \mu \mathrm{g} / \mathrm{mL}$, which is more than 100-fold higher than its MIC for planktonic cells. A slightly higher MBEC of $64 \mu \mathrm{g} / \mathrm{mL}$ was previously reported [3]. Such deviations can be accounted for by variations in the density of biofilms exposed to the antibiotic, which depends on the adopted method for biofilm formation. In the case of norfloxacin (MBEC: $160 \mu \mathrm{g} / \mathrm{mL}$ ), the concentration was almost 
$200 \times$ the MIC, and levofloxacin concentration (MBEC: $320 \mu \mathrm{g} / \mathrm{mL}$ ) was also more than $300 \times$ the planktonic MIC. Likewise, the concentration needed for gatifloxacin (MBEC: $533.33 \mu \mathrm{g} / \mathrm{mL}$ ) was more than $800 \times$ its MIC. These findings are in accordance with an earlier publication that stated that bacterial biofilms can be up to 1000-fold less susceptible than planktonic cells [31]. As evident from this study, ofloxacin (MBEC: $640 \mu \mathrm{g} / \mathrm{mL}$ ) is the least potent fluoroquinolone against $P$. aeruginosa. In that respect, current results contradict other works that reported ofloxacin as a potent antibiotic against P. aeruginosa biofilms [32,33].

For MRSA, the newer third generation FLQs (gatifloxacin and moxifloxacin) again showed the most promising results by having the lowest MBEC values among the selected FLQs. The MBECs for gatifloxacin and moxifloxacin were $328.13 \mu \mathrm{g} / \mathrm{mL}$ and $390.63 \mu \mathrm{g} / \mathrm{mL}$, respectively. In agreement with this finding, a recent study concluded that moxifloxacin treatment in an in vitro model exhibited superior anti-biofilm activity against MRSA and methicillin-resistant Staphylococcus epidermidis biofilms compared to vancomycin [34]. Norfloxacin had the highest MBEC $(875 \mu \mathrm{g} / \mathrm{mL})$, and thus was the least effective in vitro against both planktonic and biofilm bacterial cells.

It is evident from the results obtained that norfloxacin and ofloxacin were the least potent against both planktonic and biofilm cells of MRSA, while ciprofloxacin and ofloxacin were the most potent and the least potent, respectively, against both planktonic and biofilm cells of P. aeruginosa. However, the efficacy of the remaining selected FLQs on planktonic cells did not correspond to that on biofilm cells. For instance, levofloxacin was more effective against planktonic cells of MRSA than on biofilms, while ciprofloxacin was more effective against biofilms than planktonic cells. A similar trend applied to moxifloxacin and gatifloxacin against MRSA, and gatifloxacin and norfloxacin against P. aeruginosa. This was compatible with the fact that certain antibiotics are more effective against biofilms of P. aeruginosa than other antibiotics [29,30,35-38]. For example, ciprofloxacin and ofloxacin were more effective against biofilms of $P$. aeruginosa than other antibiotics such as ceftazedim, gentamicin, imipenem, amikacin, azithromycin, and erythromycin [32]. This difference in antibiotic susceptibility could be related to differences in bacterial behavior in the biofilm state as compared to that in the planktonic form. It could also be related to the chemical structures of respective antibiotics, where ciprofloxacin and norfloxacin differ in only a single chemical moiety, and moxifloxacin and gatifloxacin similarly differ in only one chemical moiety. Further analysis of the effect of the relationship of chemical structure to the activities of FLQs against bacteria in the biofilm state could be the matter of a separate future study which would take into account previous work ranging from X-ray crystallography to resistance to toxic side effects [39-41]. In that respect, it could be the case that some FLQs are more rapidly lethal, and if so, it is apparent that only the most effective FLQs should be used, since the weaker ones will select for resistance and ruin the entire class. For example, the quinolones induce the SOS response, which is mutagenic. Thus, FLQs that are highly lethal are expected to restrict the emergence of resistance better than ones that are less lethal or less potent [42,43].

The order of decreasing antibacterial activity corresponding to the diameter zones of inhibition was consistent with that found from our MIC measurements. Another issue to be considered is the basis for biofilm eradication, and the relationship between MIC and the lethal activity, especially rapid killing (not MBC). They appear to involve different mechanisms. Where the MIC is due to trapping gyrase on DNA, rapid killing arises from the release of DNA breaks and the accumulation of reactive oxygen species [44]. The MBC, on the other hand, could be reflecting other secondary reactions. More work is needed toward this end [44].

In the future, in vivo clinical studies are required for the proper assessment of the safety and efficacy of these FLQs against biofilms. An earlier study [45] reported that moxifloxacin retained a low MIC against ciprofloxacin-resistant strains of Staphylococcus aureus, although treatment with this antibiotic failed when tested against experimental models of endocarditis. This could be related to the fact that while the primary target for ciprofloxacin is topoisomerase IV, it is DNA gyrase for moxifloxacin $[46,47]$. Thus, it seems plausible that moxifloxacin will retain some activity in ciprofloxacin-resistant strains. Yet, and for unknown reasons, the resistance to one of these targets 
increases the probability that resistance will develop in the other target [48,49]. Other studies reported that FLQs may increase the risk of MRSA in hospitalized patients [50,51]. On the other hand, previous studies also reported that FLQs have potent antibacterial activities against $P$. aeruginosa biofilms $[32,52]$. Furthermore, the best antibiotic against $P$. aeruginosa among this class of antimicrobials was ciprofloxacin [18].

Taken together, current results are confirmatory of previous works and indicate that P. aeruginosa and MRSA are susceptible (either highly or moderately) to all the FLQs that were tested here, and ciprofloxacin remains the most effective.

Author Contributions: Conceptualization, M.M.M. and K.H.A.; Methodology, M.M.M. W.S.A. and A.S.M.; Validation, M.M.M., and K.H.A.; Formal Analysis, W.S.A. and A.S.M.; Investigation, M.M.M., W.S.A. and A.S.M.; Resources, M.M.M. and K.H.A; Data Curation, M.M.M., K.H.A., W.S.A. and A.S.M.; Writing-Original Draft Preparation, M.M.M., W.S.A. and A.S.M.; Writing-Review \& Editing, K.H.A.; Visualization, M.M.M., K.H.A., W.S.A. and A.S.M.; Supervision, M.M.M. and K.H.A.; Project Administration, K.H.A. and M.M.M.; Funding Acquisition, M.M.M.

Funding: This research was funded by Deanship of Research of the Jordan University of Science and Technology, Irbid, Jordan grants numbers [261/2013, 225/2013]" and "The APC was partially funded by Deanship of Research of the Jordan University of Science and Technology, Irbid, Jordan".

Conflicts of Interest: The authors declare no conflict of interest.

\section{References}

1. Høiby, N.; Bjarnsholt, T.; Givskov, M.; Molin, S.; Ciofu, O. Antibiotic resistance of bacterial biofilms. Int. J. Antimicrob. Agents 2010, 35, 322-332. [CrossRef] [PubMed]

2. Bordi, C.; de Bentzmann, S. Hacking into bacterial biofilms: A new therapeutic challenge. Ann. Intensive Care 2011, 1, 19. [CrossRef] [PubMed]

3. Masadeh, M.M.; Mhaidat, N.M.; Alzoubi, K.H.; Hussein, E.I.; Al-Trad, E.I. In vitro determination of the antibiotic susceptibility of biofilm-forming Pseudomonas aeruginosa and Staphylococcus aureus: Possible role of proteolytic activity and membrane lipopolysaccharide. Infect. Drug Resist. 2013, 6, 27-32. [CrossRef] [PubMed]

4. Fricks-Lima, J.; Hendrickson, C.M.; Allgaier, M.; Zhuo, H.; Wiener-Kronish, J.P.; Lynch, S.V.; Yang, K. Differences in biofilm formation and antimicrobial resistance of Pseudomonas aeruginosa isolated from airways of mechanically ventilated patients and cystic fibrosis patients. Int. J. Antimicrob. Agents 2011, 37, 309-315. [CrossRef] [PubMed]

5. Zafer, M.M.; Al-Agamy, M.H.; El-Mahallawy, H.A.; Amin, M.A.; Ashour, M.S. Antimicrobial resistance pattern and their beta-lactamase encoding genes among Pseudomonas aeruginosa strains isolated from cancer patients. Biomed. Res. Int. 2014, 2014, 101635. [CrossRef] [PubMed]

6. Enright, M.C.; Robinson, D.A.; Randle, G.; Feil, E.J.; Grundmann, H.; Spratt, B.G. The evolutionary history of methicillin-resistant Staphylococcus aureus (MRSA). Proc. Natl. Acad. Sci. USA 2002, 99, 7687-7692. [CrossRef] [PubMed]

7. National Nosocomial Infections Surveillance (NNIS) System. National Nosocomial Infections Surveillance (NNIS) System Report, Data Summary from January 1990-May 1999, issued June 1999. A report from the NNIS System. Am. J. Infect. Control 1999, 27, 520. [CrossRef]

8. Otto, M. MRSA virulence and spread. Cell. Microbiol. 2012, 14, 1513-1521. [CrossRef]

9. Ben, H.K.A.; Moissenet, D.; Vu, T.H.; Khedher, M. Virulence factors in Pseudomonas aeruginosa: Mechanisms and modes of regulation. Ann. Biol. Clin. 2011, 69, 393-403.

10. Strateva, T.; Mitov, I. Contribution of an arsenal of virulence factors to pathogenesis of Pseudomonas aeruginosa infections. Ann. Microbiol. 2011, 61, 717-732. [CrossRef]

11. Palanisamy, N.K.; Ferina, N.; Amirulhusni, A.N.; Mohd-Zain, Z.; Hussaini, J.; Ping, L.J.; Durairaj, R. Antibiofilm properties of chemically synthesized silver nanoparticles found against Pseudomonas aeruginosa. J. Nanobiotechnol. 2014, 12, 2. [CrossRef] [PubMed]

12. Askoura, M.; Mottawea, W.; Abujamel, T.; Taher, I. Efflux pump inhibitors (EPIs) as new antimicrobial agents against Pseudomonas aeruginosa. Libyan J. Med. 2011, 6, 5870. [CrossRef]

13. Bolon, M.K. The newer fluoroquinolones. Med. Clin. N. Am. 2011, 95, 793-817. [CrossRef] [PubMed] 
14. Oliphant, C.M.; Green, G.M. Quinolones: A comprehensive review. Am. Fam. Phys. 2002, 65, 455-464.

15. Soni, K. Fluoroquinolones: Chemistry \& Action-A Review. Indo Glob. J. Pharm. Sci. 2012, 2, 43-53.

16. Somasundaram, S.; Manivannan, K. An Overview of Fluoroquinolones. Annu. Rev. Res. Biol. 2013, 3, 296-313.

17. Emami, S.; Shafiee, A.; Foroumadi, A. Quinolones: Recent Structural and Clinical Developments. Iran. J. Pharm. Res. 2005, 4, 123-136.

18. Sharma, P.C.; Jain, A.; Jain, S. Fluoroquinolone antibacterials: A review on chemistry, microbiology and therapeutic prospects. Acta Pol. Pharm. 2009, 66, 587-604. [PubMed]

19. Manyi-Loh, C.E.; Clarke, A.M.; Munzhelele, T.; Green, E.; Mkwetshana, N.F.; Ndip, R.N. Selected South African Honeys and Their Extracts Possess In Vitro Anti-Helicobacter pylori Activity. Arch. Med. Res. 2010, 41, 324-331. [CrossRef] [PubMed]

20. Wiegand, I.; Hilpert, K.; Hancock, R.E. Agar and broth dilution methods to determine the minimal inhibitory concentration (MIC) of antimicrobial substances. Nat. Protoc. 2008, 3, 163-175. [CrossRef] [PubMed]

21. Almaaytah, A.; Qaoud, M.T.; Khalil Mohammed, G.; Abualhaijaa, A.; Knappe, D.; Hoffmann, R.; Al-Balas, Q. Antimicrobial and Antibiofilm Activity of UP-5, an Ultrashort Antimicrobial Peptide Designed Using Only Arginine and Biphenylalanine. Pharmaceuticals 2018, 11, 3. [CrossRef] [PubMed]

22. Ceri, H.; Olson, M.; Stremick, C.; Read, R.; Morck, D.; Buret, A. The Calgary Biofilm Device: New Technology for Rapid Determination of Antibiotic Susceptibilities of Bacterial Biofilms. J. Clin. Microbiol. 1999, 37, 1771-1776. [PubMed]

23. Agarwal, G.; Kapil, A.; Kabra, S.; Das, B.; Dwivedi, S. In vitro efficacy of ciprofloxacin and gentamicin against a biofilm of Pseudomonas aeruginosa and its free-living forms. Natl. Med. J. India 2005, 18, 184. [PubMed]

24. Shailaja, V.; Himabindu, V.; Anuradha, K.; Anand, T.; Lakshmi, V. In vitro activity of gatifloxacin against gram negative clinical isolates in a tertiary care hospital. Indian J. Med. Microbiol. 2004, 22, 222. [PubMed]

25. Bushra, R.; Rizvi, M.; Ahmed, M.; Alam, S.; Bano, N. In-vitro Susceptibility of Levofloxacin against Different Clinical Isolates. Pak. J. Med. Dent. 2013, 2, 8-12.

26. Adhikari, L.; Roy, K.; Tsering, D.; Pal, R.; Kar, S. Susceptibility rates of Pseudomonas aeruginosa strains to quinolones. J. Lab. Phys. 2010, 2, 121.

27. Smith, S.; Eng, R. Activity of ciprofloxacin against methicillin-resistant Staphylococcus aureus. Antimicrob. Agents Chemother. 1985, 27, 688-691. [CrossRef] [PubMed]

28. Smith, K.; Cobbs, C. In vitro activity of sparfloxacin and three other fluoroquinolones against methicillin-resistant Staphylococcus aureus and Staphylococcus epidermidis. Eur. J. Clin. Microbiol. Infect. Dis. Off. Publ. Eur. Soc. Clin. Microbiol. 1992, 11, 55-58. [CrossRef]

29. Wei, Q.; Ma, L.Z. Biofilm matrix and its regulation in Pseudomonas aeruginosa. Int. J. Mol. Sci. 2013, 14, 20983-21005. [CrossRef]

30. Donlan, R.M. Biofilm formation: A clinically relevant microbiological process. Clin. Infect. Dis. 2001, 33, 1387-1392. [CrossRef]

31. Mulcahy, H.; Charron-Mazenod, L.; Lewenza, S. Extracellular DNA chelates cations and induces antibiotic resistance in Pseudomonas aeruginosa biofilms. PLoS Pathog. 2008, 4, e1000213. [CrossRef] [PubMed]

32. Abdi-Ali, A.; Mohammadi-Mehr, M.; Agha Alaei, Y. Bactericidal activity of various antibiotics against biofilm-producing Pseudomonas aeruginosa. Int. J. Antimicrob. Agents 2006, 27, 196-200. [CrossRef] [PubMed]

33. Abidi, S.H.; Sherwani, S.K.; Siddiqui, T.R.; Bashir, A.; Kazmi, S.U. Drug resistance profile and biofilm forming potential of Pseudomonas aeruginosa isolated from contact lenses in Karachi-Pakistan. BMC Ophthalmol. 2013, 13, 57. [CrossRef]

34. Salem, A.; Elkhatib, W.; Ahmed, G.; Noreddin, A. Pharmacodynamics of moxifloxacin versus vancomycin against biofilms of methicillin-resistant Staphylococcus aureus and epidermidis in an in vitro model. J. Chemother. 2010, 22, 238-242. [CrossRef]

35. Berlanga, M.; Gomez-Perez, L.; Guerrero, R. Biofilm formation and antibiotic susceptibility in dispersed cells versus planktonic cells from clinical, industry and environmental origins. Antonie Van Leeuwenhoek 2017, 110, 1691-1704. [CrossRef]

36. Jamal, M.; Andleeb, S.; Jalil, F.; Imran, M.; Nawaz, M.A.; Hussain, T.; Ali, M.; Das, C.R. Isolation and characterization of a bacteriophage and its utilization against multi-drug resistant Pseudomonas aeruginosa-2995. Life Sci. 2017, 190, 21-28. [CrossRef] [PubMed] 
37. Waters, V.; Ratjen, F. Standard versus biofilm antimicrobial susceptibility testing to guide antibiotic therapy in cystic fibrosis. Cochrane Database Syst. Rev. 2017, 10, CD009528. [CrossRef]

38. Wang, W.; Chanda, W.; Zhong, M. The relationship between biofilm and outer membrane vesicles: A novel therapy overview. FEMS Microbiol. Lett. 2015, 362, fnv117. [CrossRef]

39. Ezelarab, H.A.A.; Abbas, S.H.; Hassan, H.A.; Abuo-Rahma, G.E.A. Recent updates of fluoroquinolones as antibacterial agents. Arch. Pharm. 2018, 351, e1800141. [CrossRef]

40. Kocsis, B.; Domokos, J.; Szabo, D. Chemical structure and pharmacokinetics of novel quinolone agents represented by avarofloxacin, delafloxacin, finafloxacin, zabofloxacin and nemonoxacin. Ann. Clin. Microbiol. Antimicrob. 2016, 15, 34. [CrossRef]

41. Zhang, G.F.; Liu, X.; Zhang, S.; Pan, B.; Liu, M.L. Ciprofloxacin derivatives and their antibacterial activities. Eur. J. Med. Chem. 2018, 146, 599-612. [CrossRef] [PubMed]

42. Cirz, R.T.; O'Neill, B.M.; Hammond, J.A.; Head, S.R.; Romesberg, F.E. Defining the Pseudomonas aeruginosa SOS response and its role in the global response to the antibiotic ciprofloxacin. J. Bacteriol. 2006, 188, 7101-7110. [CrossRef] [PubMed]

43. Stewart, P.S.; Franklin, M.J.; Williamson, K.S.; Folsom, J.P.; Boegli, L.; James, G.A. Contribution of stress responses to antibiotic tolerance in Pseudomonas aeruginosa biofilms. Antimicrob. Agents Chemother. 2015, 59, 3838-3847. [CrossRef]

44. Kiem, S.; Schentag, J.J. Relationship of minimal inhibitory concentration and bactericidal activity to efficacy of antibiotics for treatment of ventilator-associated pneumonia. Semin. Respir. Crit. Care Med. 2006, 27, 51-67. [CrossRef]

45. Entenza, J.; Que, Y.; Vouillamoz, J.; Glauser, M.; Moreillon, P. Efficacies of Moxifloxacin, Ciprofloxacin, and Vancomycin against Experimental Endocarditis Due to Methicillin-Resistant Staphylococcus aureus Expressing Various Degrees of Ciprofloxacin Resistance. Antimicrob. Agents Chemother. 2001, 45, 3076-3083. [CrossRef]

46. Blondeau, J.M. Fluoroquinolones: Mechanism of action, classification, and development of resistance. Surv. Ophthalmol. 2004, 49 (Suppl. 2), S73-S78. [CrossRef] [PubMed]

47. Al Omari, M.M.; Jaafari, D.S.; Al-Sou'od, K.A.; Badwan, A.A. Moxifloxacin hydrochloride. Profiles Drug Subst. Excip. Relat. Methodol. 2014, 39, 299-431.

48. Hooper, D.C.; Jacoby, G.A. Topoisomerase Inhibitors: Fluoroquinolone Mechanisms of Action and Resistance. Cold Spring Harb. Perspect. Med. 2016, 6, a025320. [CrossRef]

49. Luan, G.; Drlica, K. Fluoroquinolone-Gyrase-DNA Cleaved Complexes. Methods Mol. Biol. 2018, 1703, 269-281.

50. LeBlanc, L.; Pépin, J.; Toulouse, K.; Ouellette, M.F.; Coulombe, M.-A.; Corriveau, M.-P.; Alary, M.-E. Fluoroquinolones and Risk for Methicillin-Resistant Staphylococcus aureus, Canada. Emerg. Infect. Dis. 2006, 12, 1398. [CrossRef]

51. Weber, S.G.; Gold, H.S.; Hooper, D.C.; Karchmer, A.; Carmeli, Y. Fluoroquinolones and the Risk for Methicillin-resistant Staphylococcus aureus in Hospitalized Patients. Emerg. Infect. Dis. 2003, 9, 1415. [CrossRef] [PubMed]

52. Elkhatib, W.; Noreddin, A. In Vitro Antibiofilm Efficacies of Different Antibiotic Combinations with Zinc Sulfate against Pseudomonas aeruginosa Recovered from Hospitalized Patients with Urinary Tract Infection. Antibiotics 2014, 3, 64-84. [CrossRef] [PubMed]

(c) 2019 by the authors. Licensee MDPI, Basel, Switzerland. This article is an open access article distributed under the terms and conditions of the Creative Commons Attribution (CC BY) license (http://creativecommons.org/licenses/by/4.0/). 